\title{
Evasão Escolar no Ensino Superior: Análise Quantitativa no Curso de Licenciatura em Física do IFPA Campus Bragança
}

School Evasion in Higher Education: Quantitative Analysis in the Degree in Physics of IFPA Campus Bragança

\author{
F. A. Moura*1(iD, P. H. P. Mandarino ${ }^{1}$, S. C. P. da Silva ${ }^{1}$ \\ ${ }^{1}$ Instituto Federal de Educação, Ciência e Tecnologia do Pará, Bragança, PA, Brasil
}

\begin{abstract}
Recebido em 07 de fevereiro de 2020. Revisado em 29 de fevereiro de 2020. Aceito em 21 de março de 2020.
A evasão escolar é um fenômeno que atinge diretamente as instituições de ensino e causa diversos prejuízos acadêmicos, sociais e econômicos. Estudando o tema, notamos que diversos alunos ingressantes no período de 2009 a 2014, evadiram do curso de Licenciatura em Física do IFPA campus Bragança. Examinando esse contexto, identificamos e analisamos o percentual de alunos evadidos no referido curso. Os dados analisados foram obtidos por meio da Sinopse do Ensino Superior e da Secretaria Acadêmica do IFPA. Os resultados comprovam que a evasão no curso analisado, se sobrepõe às médias nacionais e expõe a necessidade de intensificarem as políticas públicas para garantir o acesso, permanência e êxito dos alunos ingressantes.
\end{abstract}

Palavras-chave: Licenciatura em Física, Evasão Escolar, Ensino Superior.

\begin{abstract}
School dropout is a phenomenon that directly affects educational institutions and causes various academic social and economic damages. Studying the subject, we noticed that several students entering the period from 2009 to 2014, have escaped from the Licentiate degree in Physics of the IFPA campus Bragança. Analyzing this context, identify and analyze the percentage of students evaded in said course. The data analyzed were obtained through the Synopsis of Higher Education and the Academic Secretary of IFPA. The results show that dropout in the analyzed course overlaps the national averages and exposes the need to intensify public policies to guarantee the access, permanence and success of incoming students.
\end{abstract}

Keywords: Degree in Physics, School Evasion, Higher education.

\section{A EVASÃO ESCOLAR NOS CURSOS DE LICENCIATURA}

A evasão é um problema internacional que gera diversas perdas sociais, acadêmicas e econômicas, sendo raras as Instituições de Ensino Superior (IES) que possuem um programa que busque formas de solucionar e combater essa adversidade 1].

No decorrer dos anos, observamos os baixos índices de alunos que concluíram o curso e, consequentemente, a elevada taxa de evasão escolar. No Curso de Licenciatura em Física do IFPA, no campus Bragança, a evasão média, no período de 2009 a 2012, é de 54,92\% [2].

Mediante essas informações, a presente pesquisa tem por objetivo quantificar, identificar e analisar o índice de evasão escolar no curso de Licenciatura em Física do IFPA campus Bragança; comparar os resultados desta pesquisa com as taxas de evasão anual média, nos cursos de Licenciatura em Física no Brasil, na modalidade presencial das universidades públicas, através da sinopse do

*Endereço de correspondência: fabio.moura@ifpa.edu.br
Ensino Superior, divulgada pelo Instituto Nacional de Estudos e Pesquisas Anísio Teixeira (INEP).

A evasão pode ser entendida através da evasão anual. evasão anual média e a evasão total. A evasão anual serve para identificar os alunos que desistiram a cada ano/período; a evasão anual média identifica a média das evasões durante um período específico e a evasão total analisa a relação entre a quantidade de alunos que ingressaram em um determinado curso e os que não obtiveram diploma após a conclusão do período do curso [1].

A partir destas definições, realizamos um levantamento de dados, que foram coletados a partir das planilhas da sinopse do ensino superior, fornecidas pelo INEP. A Tabela 1 evidencia os percentuais da evasão, que são medidos através das relações entre o número de ingressantes, matriculados e concluintes por período, nos cursos de licenciatura, comparando ao curso de licenciatura em Física.

Analisando os resultados encontrados na Tabela 1. notamos que nos cursos de licenciatura presenciais em IES públicas do Brasil gerou uma taxa de evasão anual 
Tabela 1: Percentual de evasão anual para cursos de licenciatura presenciais em IES públicas. Fonte: Autores (2019), a partir dos dados das Sinopses do Ensino Superior (Brasil, 2018).

\begin{tabular}{lcc}
\hline \multicolumn{3}{l}{ Evasão anual em cursos de Licenciatura } \\
\hline Ano & Licenciaturas & Física \\
\hline 2014 & $15,55 \%$ & $30,67 \%$ \\
\hline 2015 & $17,15 \%$ & $28,19 \%$ \\
\hline 2016 & $13,52 \%$ & $27,40 \%$ \\
\hline 2017 & $15,79 \%$ & $28,81 \%$ \\
\hline
\end{tabular}

média de 15,50\%, no período de 2014 a 2017, e, nos cursos de Licenciatura em Física, 28,0\%.

\section{Resultados e discussões}

Analisando o curso de Licenciatura em Física no Brasil, a partir da Tabela 1. percebemos que a evasão anual média é de $28,77 \%$ e, comparando com as demais licenciaturas, o índice de evasão anual média é de 15,50\%. Os dados citados comprovam que a evasão no curso de Licenciatura

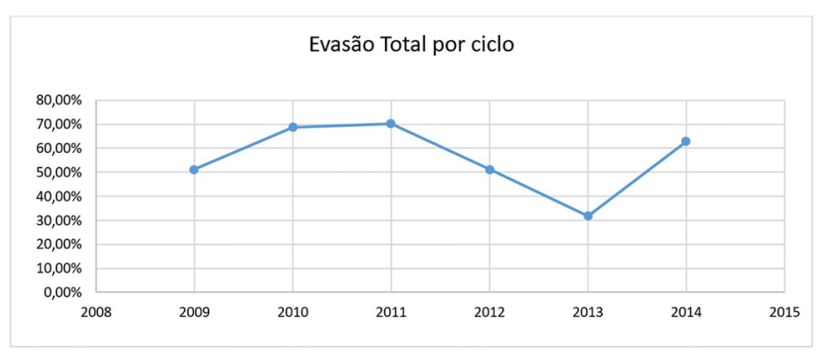

Figura 1: Evasão total no curso de Licenciatura em Física do IFPA campus Bragança. Fonte: Autores (2019), a partir dos dados do SIGAA do IFPA. em Física é maior quando comparado com outros cursos de licenciatura.

A partir da quantificação, identificação e análise dos dados analisados através do SIGAA, constatamos que o índice de evasão média é de 55,27\% no curso de Licenciatura em Física do IFPA campus Bragança. Os valores da evasão total, por ciclo, constam na Tabela 2

Os dados da Tabela 2 são valores da evasão total por ciclo, e, neste caso específico, os alunos definidos como "em curso" não constam como "evadidos" e nem como "concluintes".

Podemos comparar a evasão média no curso de Licenciatura em Física do IFPA, com a evasão anual média das Licenciaturas em Física no Brasil, que apresentam os valores de $55,27 \%$ e $28,77 \%$, respectivamente. Analisando a Tabela 2 constatamos a evolução dos índices de evasão total por ciclo das turmas do curso de Licenciatura em Física do IFPA campus Bragança que está apresentado na Figura 1

Para compreendermos em que momento ocorreram as evasões nas turmas em estudo, realizamos análises individuais nos históricos escolares dos alunos evadidos. Depois de feitas as análises, percebemos que é no primeiro semestre (período) de curso que ocorrem os maiores índices de evasão. Esses informes estão disponíveis na tabela 3, que organiza as informações por semestre letivo.

Os dados da tabela 3 afirmam que a taxa de evasão no primeiro semestre de curso, é de duas a três vezes maior do que a dos anos seguintes [1]. A partir dos dados da Tabela 3, calculamos o percentual de evasão escolar por semestre letivo, considerando todos os alunos evadidos. Estas informações estão resumidas na Figura 2

De acordo com a Figura 2 constatamos que $56 \%$ dos alunos evadidos, abandonam o curso no primeiro semestre letivo, ou seja, mais da metade dos discentes evadem

Tabela 2: Valores totais dos alunos por categoria e ano. Fonte: Autores (2019) a partir dos dados do SIGAA do IFPA.

\begin{tabular}{|c|c|c|c|c|c|}
\hline \multirow{2}{*}{$\begin{array}{l}\text { Ano de } \\
\text { ingresso }\end{array}$} & \multirow{2}{*}{$\begin{array}{l}\text { Número de } \\
\text { ingressantes }\end{array}$} & \multirow{2}{*}{$\begin{array}{l}\text { Número de } \\
\text { concluintes }\end{array}$} & \multirow{2}{*}{$\begin{array}{c}\text { Número de } \\
\text { em curso }\end{array}$} & \multicolumn{2}{|c|}{ Evadidos } \\
\hline & & & & Número & Percentual \\
\hline 2009 & 43 & 21 & 0 & 22 & $51,16 \%$ \\
\hline 2010 & 32 & 10 & 0 & 22 & $68,75 \%$ \\
\hline 2011 & 37 & 11 & 0 & 26 & $70,27 \%$ \\
\hline 2012 & 41 & 19 & 1 & 21 & $51,21 \%$ \\
\hline 2013 & 41 & 26 & 2 & 13 & $31,71 \%$ \\
\hline 2014 & 43 & 12 & 4 & 27 & $62,79 \%$ \\
\hline TOTAL & 237 & 99 & 7 & 131 & $55.27 \%$ \\
\hline
\end{tabular}

Tabela 3: Evasão dos alunos por semestre letivo. Fonte: Autores (2019), a partir dos dados do SIGAA do IFPA.

\begin{tabular}{cccccccc}
\hline \multirow{2}{*}{ Ano } & $\begin{array}{c}\mathbf{1}^{\mathbf{O}} \\
\text { Semestre }\end{array}$ & $\begin{array}{c}\mathbf{2}^{\mathbf{O}} \\
\text { Semestre }\end{array}$ & $\begin{array}{c}\mathbf{3}^{\mathbf{O}} \\
\text { Semestre }\end{array}$ & $\begin{array}{c}\mathbf{4}^{\mathbf{O}} \\
\text { Semestre }\end{array}$ & $\begin{array}{c}\mathbf{5}^{\mathbf{o}} \\
\text { Semestre }\end{array}$ & $\begin{array}{c}\mathbf{6}^{\mathbf{o}} \\
\text { Semestre }\end{array}$ & \multirow{2}{*}{ Outros } \\
\hline 2009 & 10 & 4 & 2 & 1 & 0 & 0 & 4 \\
\hline 2010 & 13 & 3 & 2 & 0 & 0 & 0 & 4 \\
\hline 2011 & 15 & 8 & 2 & 0 & 0 & 0 \\
\hline 2012 & 12 & 5 & 4 & 0 & 0 & 0 & 0 \\
\hline 2013 & 6 & 1 & 5 & 0 & 1 & 0 & 0 \\
\hline 2014 & 17 & 5 & 4 & 0 & 0 & 0 & 0 \\
\hline TOTAL & $\mathbf{7 3}$ & $\mathbf{2 6}$ & $\mathbf{1 9}$ & $\mathbf{1}$ & $\mathbf{2}$ & $\mathbf{1}$ & $\mathbf{8}$ \\
\hline
\end{tabular}




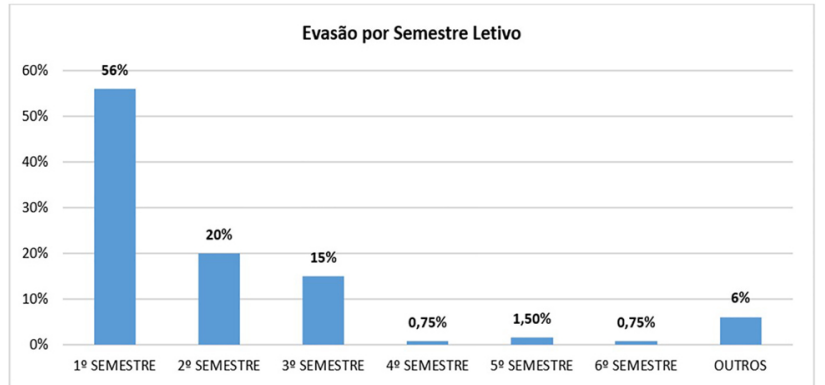

Figura 2: Percentual total dos alunos evadidos por semestre letivo. Fonte: Autores (2019), a partir dos dados do SIGAA do IFPA.

no início do curso. Este problema também é encontrado nos demais semestres, porém com taxas inferiores. Podemos destacar que, no segundo semestre, a taxa de evasão corresponde a $20 \%$, este valor está duas vezes menor em comparação ao primeiro semestre, como previsto por Silva Filho e Lobo [3]. Nos demais semestres, esta evasão continua caindo. Portanto, podemos interpretar esta situação da seguinte maneira: os primeiros semestres são decisivos para os alunos, são onde eles decidem continuar ou desistir; quanto mais próximo ao término do curso, menor é o índice de evasão.

\section{Considerações Finais}

A evasão é tratada como um fenômeno que pode gerar diversos fatores negativos à sociedade e causar prejuízos enormes para a economia do país, pois, o governo disponibiliza investimentos para custear as IES, a fim de que elas proporcionem educação de qualidade, mas que, por outro lado, acaba não formando professores o suficiente para suprir a demanda da educação básica, além dos prejuízos para o próprio aluno, visto que, quando ele se evade, acaba por se frustrar ao não alcançar seus objetivos.

Todas as instituições de ensino sofrem com as consequências negativas relacionadas à evasão escolar. Em vista disso, é de sumo interesse destas instituições identificarem quando e por que esta evasão ocorre.

Analisando esse contexto, diversos pesquisadores publicaram trabalhos com essa temática que contribuíram para que esta pesquisa alcançasse os objetivos [4], [5], [6], [1].

Ao analisarmos a evasão, percebemos que em sistemas globais, há a necessidade do tratamento estatístico dos dados (número de ingressantes, matriculados e concluintes) da sinopse do ensino superior divulgado pelo INEP para calcular as diversas formas de evasão. Para os sistemas específicos e/ou particulares, como no caso do IFPA, medimos a evasão por ciclo de turma e a evasão média para podermos comparar com os dados nacionais que evidenciaram os índices de evasão (por ciclo e médio), maiores que as médias nacionais.
Percebemos, no decorrer da pesquisa, que conseguimos quantificar, identificar e analisar a evasão no curso de Licenciatura em Física do IFPA campus Bragança que teve sua evasão anual média de 55,27\%. Esta evasão se mostrou acima das médias nacionais relacionadas aos cursos de Licenciatura em Física no Brasil $(28,77 \%)$ e em todas as Licenciaturas no Brasil (15,50\%).

Evidenciamos que a maior parte da evasão, no caso específico desta pesquisa, ocorreu durante o primeiro e segundo semestres letivo com médias de $56 \%$ e $20 \%$, respectivamente. Estes fatos, que foram obtidos a partir de dados oficiais, são corroborados por [3] e [1]. Ainda de acordo com esses dados, foi possível notar que a evasão escolar é uma adversidade encontrada no IFPA campus Bragança.

Para concluir, sugerimos o aprofundamento desta pesquisa, a fim de identificarem os motivos e as causas da evasão; identificarem os agentes causadores da evasão nos primeiros semestres; e intensificarem as políticas públicas para a conclusão e êxito do curso de Licenciatura em Física.

\section{Referências}

[1] R.L.L. Silva Filho, P.R. Montejunas, O. Hipólito e M.B.C.M. Lobo, Cadernos de Pesquisa 37, 641 (2007).

[2] P.H.P. Mandarino, S.C.P. Silva e F.A. Moura, em Anais do II Congresso Nacional de Pesquisa e Ensino de Ciências, Campina Grande, 2017 (Editora Realize, Campina Grande, 2017), p. 1-3.

[3] R.L.L. Silva Filho e M.B.C.M. Lobo, Como a mudança na metodologia do INEP altera o cálculo da evasão, disponível em https://www .institutolobo.org. br/imagens/pdf/artigos/art_079.pdf, acessado em $18 / 02 / 2018$

[4] M.F. Barroso e E.B.M. Falcão, em Atas do IX Encontro de Pesquisa em Ensino de Física, Jaboticatubas, 2004 (SBF, Jaboticatubas, 2004).

[5] P.R.M. Lima Junior, Evasão do ensino superior de física segundo a tradição disposicionalista em sociologia da educação. Tese de Doutorado, Universidade Federal do Rio Grande do Sul, Porto Alegre (2013).

[6] B. Sampaio, Y. Sampaio, E.P.G Mello e A.S. Mello, Economia Aplicada 15, 287 (2011). 